\title{
Methodological Approaches to Assessing the Regulatory Impact of the State in the Innovation Development Sphere of Market Services
}

\author{
Regina R. Kharisova ${ }^{1}$, Sergey V. Kiselev ${ }^{2}$, Natalia M. Chikisheva ${ }^{3}$, Lyudmila G. Rudenko ${ }^{4}$, Irina A. Astafyeva ${ }^{5}$, \\ Viktoriya L. Grankina ${ }^{5} \&$ Larisa V. Khabibullina ${ }^{1}$ \\ ${ }^{1}$ Kazan State University of Architecture and Engineering, Kazan, Russia \\ ${ }^{2}$ Kazan National Research Technological University, Kazan, Russia \\ ${ }^{3}$ Tyumen state University of Architecture and Construction, Tyumen, Russia \\ ${ }^{4}$ Moscow University named by S.Y. Witte, Moscow, Russia \\ ${ }^{5}$ Moscow State University of Mechanical Engineering, Moscow, Russia \\ Correspondence: Regina R. Kharisova, Kazan State University of Architecture and Engineering, 420043, \\ Zelenaya Street, 1, Kazan, Russia. E-mail: rida@mail.ru
}

\author{
Received: April 16, 2015 Accepted: April 26, 2015 Online Published: May 28, 2015 \\ doi:10.5539/jsd.v8n3p194 URL: http://dx.doi.org/10.5539/jsd.v8n3p194
}

\begin{abstract}
The acceleration of the transition of the Russian economy to an innovative way of development largely depends on the innovativeness in the services sector. The efficiency of the services sector and its innovation development cannot be addressed without consideration of the regulatory role of the state and the assessment of this role. However, there is still no comprehensive study of this problem; there is only coverage of some aspects of the problem and fragmented presentation of its individual aspects. The article analyzes the causes for the need of the state influence on the innovation development of services, methods of regulatory impact assessment (RIA) by industry, including the service sector, highlights the stages of the development of the RIA methodology, systematizes theoretical approaches to the regulatory impact assessment by the state. All this allowed the authors to justify a system of principles and directions of research within the logic of RIA, a set of methods and tools for collecting, processing and analyzing data, forming a methodology for the use of RIA, a system of criteria and indicators of the realization of the RIA goals. This article is intended for researchers, teachers and graduate students studying the problems of regulatory impact assessment of a state on innovation, as well as specialists of the state bodies dealing with the problems of improving the regulatory impact assessment of the state.
\end{abstract}

Keywords: regulatory impact assessment, innovation development, services sector, methodological approaches

\section{Introduction}

The acceleration of the transition of the Russian economy to an innovative way of development largely depends on the innovativeness in the service sector and is a direct result of its high-tech and knowledge-based industries (Egorov, 2010). In the service sector these include modern types of transport and communications, education, healthcare, business services, including software development, consulting, marketing, financial services, other services used in the organization and conduct of business (Gilyazutdinova, Kiselev, Faizrakhmanov, 2013).

In foreign practice in the service sector there are three main sections: services as purely public goods; services of natural monopolies; services as private goods. Two of the last sections are the basis of the services market sector. These sections and their ratio determine the peculiarities of state regulation, and their considered choice, as noted by J. Stiglitz, largely determines the level of socio-economic efficiency of the national economy (Stiglitz, 1997).

Indeed, the effectiveness of the services sector and its innovation development cannot be addressed without consideration of the regulatory role of the state and evaluation of this role (Kozlovskaya, Elmurzayeva, 2012). However, there is still no comprehensive study of this problem, there is only coverage of some aspects of the problem and fragmented presentation of its individual aspects. At the same time, the scope of services currently is acting as the most important sector of the national economy and determines the level of innovation development of primary production (Gilyazutdinova, 2008). 


\section{Methodological Framework}

The objectives of the research were the methodical substantiation of the state regulatory impact assessment in the sphere of the innovation development of market services, systematization of theoretical approaches to the regulatory impact assessment of the state, the identification of the causes leading to the need of state influence on the innovation development of services, justification of the stages in the development of methodological approaches to RIA, comparative characteristics of different methodological approaches to the regulatory impact assessment, justification of the principles and the application conditions for RIA methods and indicators.

\section{Results}

\subsection{The Main Reasons for the Need of State Influence on Innovation Processes in the Services Sector Have Been} Substantiated

As the main reasons that necessitate state influence on the innovation development of services, the professionals (Gilyazutdinova, 2008) emphasize the following:

- significant differences in the level of innovation development and in the development of market relations in various sectors of the service sector;

- presence of large-scale externalities, both positive and particularly negative ones that fall out of the scope of the market mechanism;

- presence, in addition to market segments, of services predominantly non-market, public goods, the supply of which is regulated by the state;

- necessity of achieving and maintaining an optimal balance between the private and public sectors in the provision of services;

- existence of natural monopoly on the part of the state in a number of important services;

- lack of own funds and significant investments in innovation of a number of service industries and others.

As you can see, updating even some peculiarities of the market services sector testifies to the objective necessity of state regulation in this sector, given that the production services occupy a significant share and define innovation development of primary production, this need increases significantly. Therefore, in the field of state regulation in the sector of services, the urgent tasks to be solved are the creation of a system legal framework and policy, defining of innovative activity in this area, as well as a system for evaluating the impact of this policy and measures of the state influence on various activities in this economic sector.

\subsection{The Development Stages of the Regulatory Impact Assessment Methodology Have Been Formed}

According to the foreign practice, for the successful development of innovative activity and innovation in the services sector, as well as in any field, you need a clear, transparent and effective regulatory environment, which today in the domestic economy does not yet exist. Under RIA the researchers (Tsygankov, 2010) understand a process of the feedback formation of the state structures-developers of innovative programs, policies in the sphere of the services sector with the public, business, innovative entrepreneurship, resulting in the inspection and analysis of incoming and previously adopted requirements by the state agencies. Currently there are quite many methods of regulatory impact assessment, but the RIA assessment system has so far got a weak distribution by industry, including the service sector. This requires a balanced complex influence of the state on the process of its innovation development, and for the selection and justification of optimal variants of exposure it is necessary to have a proper system of assessment (as a tool for increasing the effectiveness of the impact), which must rely on a developed, methodologically secure concept.

In recent years significant experience in the field of RIA has been accumulated, respectively, the ideas about this procedure and the essence of the content of the word "evaluation" have been changing. The study shows that experts identify four stages in the development of the RIA methodology (Belyaev, Derman, Tsygankov, 2011).

The first stage was mainly focused on taking measurements ("measurement"). The basis of the measurements was to conduct a variety of tests, during which attention was paid to the leading elements of the evaluation. The most frequent were the studies, the main tools of which were various polls. As a significant impetus to the development of the system of regulatory impact assessment have served achievements in social and managerial sciences, as well as the promotion of scientific management in production and economic sphere. This caused the need to identify evaluation methods that are most productive and reliable.

In the second stage, called "description", in the evaluation, the assessment of the objectives and outcomes of the work are put forward. The main objective of the evaluation at this stage was that alternative projects that 
improve regulatory measures and their implementation programs were developed and put forward. At this stage a system of evaluation of programs begins to form, the advantages and disadvantages of regulatory actions in accordance with goal setting are identified.

The third stage in the development of RIA - is an "expert opinion". At this stage, the content and functions of the first two stages were completed with new aspects. Now not only the projects, programs were considered, the evaluation system was held and delivered to the purposes set in them, for which there were developed and implemented the standards of evaluation.

The fourth stage - is "coordination". At this stage, the role of the professionals involved in the assessment of regulatory measures is changing, as well as of professionals, developing a project, a program. RIA is being formed as collaboration on the design of a project, a program; the evaluation process becomes peer-coaching for all the research participants and evaluation of public projects and programs. It should be noted that peer-coaching largely depends on the communication skills of the participants, the desire to share information and receive it.

The fifth, today's stage - is "mediation". According to D. Colley (Caulley, 1993), at this stage of development of RIA the self-evaluation process can be distinguished, the subjects of which are the developers and the program participants themselves. Performers of the process of evaluation determine goals for the input of the assessment and the evaluation results, which are expected to be received at the output. Self-evaluation can be both individual and group. And also the jointly conducted studies that imply the involvement of all participants in the evaluation of a program or policy, which, in their opinion, is not sufficiently effective. The analysis of all possible fields that somehow could affect the course of program implementation is carried out.

\subsection{The Content and Benefits of the Logical Framework Approach to Regulatory Impact Assessment in the Innovation Sphere Have Been Substantiated}

Currently we can distinguish several theoretical approaches to the RIA of the state. The most commonly used is the logical-functional approach to the assessment of the RIA. In this approach it is possible to allocate different elements of assessment on the principle of expediency of their application for evaluation at any particular stage of the state program, policy, legislative act. Each type of the assessment has its own functions, corresponding characteristics that define the logic being used at a certain stage of RIA. The main elements of the logical-functional approach usually include such types of assessment as preliminary assessment, determining the degree of "estimability", the accompanied assessment, the final assessment and meta-assessment.

As noted by D.B. Tsygankov, the complicated nature of the regulation, as well as the continued increase in the number covered by RIA projects of regulation required more and more resources for the assessment. In response, the ministries and agencies responsible for the preparation of RIA, again started to reduce the quality of assessing, including that they were conducting it in formal way. According to the research results, it was decided to formalize the analysis of the quality of RIA as a mandatory procedure for all the conducted RIA. Therefore, the mechanism of meta-evaluation (monitoring) of the quality of the RIA statements should be integrated into the system of regulatory impact assessment (Tsygankov, 2010). As you can see the logical-functional approach is based on the analysis of the functions of RIA according to stages and directions that allow setting the functional potential of innovative programs, policies, regulatory measures and optimizing their implementation. If the logical-functional approach in the assessment and analysis of the regulatory impacts focuses on functions, the logical framework approach establishes a causal connection between the RIA tools and the solution to the problem to which it is directed. The logical framework approach is a management tool used primarily in the development, monitoring and evaluation of international projects. Today the logical framework approach is actively used in the field of public administration and evaluation of the implementation of the state innovation programs (policies, projects) in different sectors of the economy.

The basis of the logical framework approach is the formation of the RIA scheme: preliminary development design, identification of the central issues and cause-effect relationships, the search for alternative options to achieve the intended goal. This approach consists of two phases. The first is the analytical phase, based on the definition of the concerned parties, identification of their expectations from the proposed action, reconsideration and clarification of the goals of the impact. The second - is the phase of planning, which is a logical sequence of systematized practical actions for the movement in time to the intended results that we expect with the resources available, given the uncertainties and risk factors. The structure of the phases and the stages of implementation of the logical framework approach in the regulatory impact assessment are presented in table 1.

Drawing on the research of O.V. Kozlovskaya and R.A. Elmurzaeva (2012) we can highlight the following key points of the logical framework approach in the regulatory impact assessment: 
- according to the approach in the regulatory impact assessment, the concerned parties analysis is major;

- it is necessary to note the complexity of the process of setting, structuring and analysis of the problem, which is introduced by the regulatory impact. This is determined by the presence of different and contradictory points of view of the concerned parties in solving this problem. While it is important to identify the major problem associated with the strategic goal;

- a key element of the ongoing analysis of the problem is figuring out in which direction there will be a change in the problem, if not to implement the regulation, it is necessary to identify the shortcomings of the existing regulation of the analyzed object;

- target analysis allows determining the direction of the logic of the regulatory impact on the problem and correcting its underlying reasons or reducing their negative impact;

- successful setting and achievement of the general objective is directly dependent on the clarity and definite formulation of the aggregate of the subsidiary goals, which suggests using the following criteria: specific goals, measurable objectives, achievable goals, goal relevance, time coherence;

- search and analysis of alternatives of the regulatory impact creates opportunities to determine the best tools for managing and optimizing the likely social, economic and environmental effects.

Table 1. Diagram of the logical framework approach to regulatory impact assessment in innovation

\begin{tabular}{|c|c|}
\hline & \\
\hline $\begin{array}{l}\text { Stage 1. The concerned parties analysis: } \\
\text { - identification of the concerned parties; } \\
\text { - identification of their major challenges, constraints and } \\
\text { opportunities. } \\
\text { Stage 2. The problem analysis: } \\
\text { - formulation of problems; } \\
\text { - identification of causal relationships; } \\
\text { - formation of a "problem tree" } \\
\text { Stage 3. The goal analysis: } \\
\text { - allocation of the goals of the established problems; } \\
\text { - definition of the "means to achieve - the end result" } \\
\text { relations; } \\
\text { - unification of the goals in groups; } \\
\text {-formation of a "tree of objectives"; } \\
\text { - definition of the program strategy, policy, and project } \\
\text { Stage } 4 \text {. The definition of the participation logic: } \\
\text { - definition of the component parts of the project; } \\
\text { - checking of its logic; } \\
\text { - formulation of the objectives and their measurability }\end{array}$ & $\begin{array}{l}\text { Stage 5. The indication of the assumptions and risk } \\
\text { factors: } \\
\text { - identification of the conditions with potentially } \\
\text { negative impact on the regulatory measures. } \\
\text { Stage 6. The definition of the indicators: } \\
\text { - definition of the measurable goals; } \\
\text { - identification of the ways to measure the progress } \\
\text { when running the program, implementing the } \\
\text { policies; } \\
\text { - formation of the indicators; } \\
\text { - definition of the measurement tools; } \\
\text { Stage 7. Drawing up action plans: } \\
\text { - planning of specific activities; } \\
\text { - establishing their logical sequence and interrelation; } \\
\text { - setting milestones and assigning responsibilities; } \\
\text { Stage 8. Allocation of the resources: } \\
\text { - determining the adequacy of the resources; } \\
\text { - distribution of funds by program units; } \\
\text { - transfer of funds to expense categories; } \\
\text { - identification of the sources of funding. }\end{array}$ \\
\hline
\end{tabular}

Thus, the advantages of the logical framework approach are that it integrates all the key components of the project or a program into a system, which suggests the possibility of achieving a positive synergistic effect. Their systematization in concise form and strict sequence provide an opportunity to explain and demonstrate the logic what is the implementation of the projects/programs. So, on this basis we can identify the dependence between the different levels of the results (objectives, outputs, products). The logical framework approach makes it possible to "separate" the results of various levels and various concerned groups. In order to achieve such clarity with all the participants, it makes sense to form a logical structure involving the joint participation of the concerned parties in the discussion of all the terms and risks. 
Thus, the use of the logical framework approach in RIA leads to structuring and focus of the regulatory impact through team interaction of the participants. This approach creates the possibility to concretize the idea of organizational and social mechanisms of interaction of business, government and society, both at the stage of decision making, and at the stage of control of execution of the administrative actions.

\subsection{The Content and the Advantages of the Project Approach to the Regulatory Impact Assessment in the} Innovation Sector Have Been Substantiated

In recent years, increasingly expressed is the view that RIA should be considered as a managerial innovation, and the introduction of RIA - is a classic project, which should be implemented from the perspective of the project approach (Tsygankov, 2010). Today it is one of the most progressive methodological approaches to the implementation of targeted activities of the state. The application of project management methodology is highly productive, as it is intended to implement non-repetitive, unique, as for the set of attributes, activity in the conditions of uncertainty and instability of the external environment. As it is noted in management research, the project-oriented technology allows formulating a goal, making a prediction of the results of the project, defining the scope of works, considering the relationship and impact of the external environment and the participants on the project, introducing this impact as a system of risks.

The project approach to implementation of RIA requires consistent, interrelated implementation by the relevant authorities of a number of organizational and methodological procedures (processes), and aimed at the achievement of goals for each innovative program, policy, providing for the regulatory impact.

The application of the methodology of the project approach in RIA provides benefits to various categories of the concerned parties and allows the state to improve validity and reliability of planning and, consequently, full implementation of RIA projects and programs, control over the expenditure of funds, resources, and deadlines, to reduce the likelihood of risks, costs of the resources and time costs, transparency, reduction of expenses of budgets of all levels, improve the efficiency of the state's influence, reduce opportunities for corruption, increase in economic security and growth of innovation performance and innovative activity.

In domestic practice the concept of the project approach is widely applicable to the use of the program-target method of managing the implementation of complex target programs aimed at achieving certain social and economic objectives. This concept became popular in the innovation sector of services. It should be noted that the project approach in RIA implements traditional areas of evaluation and research of regulatory impacts that were discussed above, simultaneously complementing and refining the field of research and assessment. But its main value lies in the fact that the RIA assessment itself serves as an innovative project, and it allows using the basic principles and directions of research within the project-based approach that fit the logic of the RIA.

\subsection{The System of the Principles of the Regulatory Impact Assessment Has Been Formed}

The system of the RIA principles includes the following areas of research and evaluation:

- the principle of selective evaluation consists in state support of the innovative projects in priority areas of science and technology, including the targeted support of innovators;

- the principle of target orientation of projects and programs is expressed in ensuring ultimate goals, namely, in establishing relationships between the concerned parties;

- completeness of evaluation - implementation of the full cycle of RIA, involving a comprehensive study of the regulatory document;

- the principle of RIA gradualism means the estimation of the full cycle of each stage of the formation and implementation of the project;

- the principle of multivariance for the generation of alternatives allows taking into account the impact of factors in conditions of uncertainty, which increases in response to the growth of innovative activity;

- the principle of consistency involves the assessment of the program, a project, policy, based on the analysis of the internal relationships between elements as a system and in conjunction with the development strategy of the country as a whole;

- the complexity principle means that all the elements of the structure of the program, policy, project must be linked to one another and ensure achievement of sub-goals, in accordance with the general (common) goal.

The principles of project management in RIA define the detailed analysis of the internal and external conditions for the implementation of regulatory measures, risk analysis and development of the project team thinking among the concerned parties, thus, the fundamental difference of the project approach from other approaches is 
that all of the works in the process of regulatory impact assessment of the state are planned and produced as a structured system, as a single integrated program through specially integrated concerned groups that fall under the scope of the program impact with quite high centralization of the management in the structure (the body), which is properly empowered. In this case, the innovative nature of RIA as a project manifests itself most fully. A feature of RIA as an innovative project and methodology of the project-based approach in respect to the impact assessments is their goal-setting in accordance with the general purpose and goal orientation to obtain the final strategic result with regard to possible risks and limitations.

\subsection{Grounds Have Been Established for the Use of the Methods and Indicators in the Regulatory Impact Assessment}

Regulatory impact assessment, like any impact assessment, involves the use of a particular set of methods for collecting, processing and analyzing data, forming a methodology for the use of RIA. This primarily relates to methods of selecting a hypothetically alternative situation. The method issue - is central to the RIA, as with any other assessment, since it is the choice of the appropriate methodology that ensures the overall quality level of analysis and guarantees the implementation of its functions by RIA. Basic analytical methods used in the assessments are the analysis of "cost-benefit" and "cost-effectiveness". Both methods are used in the study of the formed alternatives to regulation and brought up for discussion. Other methods are also used, such as multivariate analysis. In this case, the depth of analysis depends on the severity of the problem, availability of the necessary information, the expected net impact and the costs for carrying out the analysis (Belyaev, Derman \& Tsygankov, 2011).

It should be noted that there need to be the criteria for evaluating programs, policies that are not currently developed. And therefore, when an innovative program is being analyzed, an innovative project, it appears that other normative regulations and norms that are not related to the case, also affect the regulated processes that is largely felt by business and other concerned parties. But the criteria and indicators, by which it is possible to determine the fact that the purpose of the regulation is not being implemented, have not been developed yet. First of all, the indicators are needed to understand whether the implementation of the program is going on by the planned scenario. If the indicators show that the goal may not be achieved, the analysis of the reasons for the ineffectiveness of the program begins: was there a mistake in the design of the policy or all the fault falls on the weak implementation of the established initiatives. To answer these questions we need a system of indicators. As a matter of fact, a detailed study of the system of indicators is beyond the RIA. However, in the manual on the RIA it is noted that the key indicators for measuring at least overall policy objectives should be described. The indicators should be designed to meet the criteria of RACER-analysis. Thus, as the experts (Belyaev, Derman \& Tsygankov, 2011) note, the indicators must be relevant, that is consistent with the purposes of the research, approved by the implementers of the program, clear to non-experts, unambiguous and easy to interpret, easy to monitor, resistant to manipulation. Only then we can say that the system of indicators can accurately reflect the real state of the policy implementation.

Analysis of the "cost-benefit" (quantitative analysis) involves identification and translation into the form of money (monetization) of as many of the costs and benefits of all the concerned parties as possible, the occurrence of which is associated with regulatory measures. In the framework of this approach all the anticipated costs and benefits can be compared, both in quantitative and qualitative terms. If the results of comparing the costs and benefits, their balance, are positive, the implementation of the regulatory project will be approved. The advantage of using this method is that it allows you to maximize the net social benefit, as in the resource-limited settings it allows you to identify the possibilities of such their distribution that maximize the net social benefits. Decisions on matters of regulatory impact assessment may have both positive and negative effects; therefore, the analysis of cost-benefit creates opportunities for the inclusion of aggregated public interest. In terms of innovation it is particularly important, as innovation affects the interests of almost all the spheres of human activity. Analysis of "cost-effectiveness" in the RIA of the innovation processes involves the calculation of the index of the projected costs to achieve the desired (alleged) social, innovation and economic effects. The peculiarity of this method is that in contrast to the above method of "cost-benefit", it gives an opportunity to choose the solutions that minimize the costs of prevention and elimination of the predicted risks. Quantitative analysis of the magnitude of the perceived risks resulting from the regulatory impact on the innovation sphere allows you to find a route and directions to reduce them. At the same time, it is necessary to pay attention to the fact that at the center of the analysis - is to prevent and reduce the inevitable risks associated with the regulation of the innovation activity. This method affects neither the assessment of the costs associated with prevention and risk reduction, nor the assessment of the public interests. Analysis of the situations of increasing or reducing specific risks within the set time period is performed by using qualitative and quantitative tools (Belyaev, 
Derman \& Tsygankov, 2011).

As you can see, these two methods complement each other and to complete the analysis it is reasonable to use them in combination.

Finally, another method, a multivariate analysis of costs and benefits includes several analytical procedures. It is normally used for analysis of complex alternatives, the implementation of which is estimated simultaneously in quantitative, qualitative and monetary expressions, as well as for alternatives with variables with a high degree of uncertainty. Therefore, there are different evaluation criteria with certain weights. The issuance of multifactor models is always individual for researchers. This is both a benefit and a disadvantage of the method. On the one hand, only this method allows you to make a comprehensive comparison of all the alternatives with each other. On the other hand, the creation of a multi-factor model, and the empowerment of the variables with defined weights - is always subjective. To reduce subjectivity pair-wise comparisons of the equally measurable factors are sometimes conducted, additional quantitative substantiations are provided for the accepted weights.

Nevertheless, whatever criteria is used, the assessment result should always be the selection of one of the alternatives as the most effective way of implementing the policy. Finally, the final phase of the RIA is to develop indicators according to which the assessment of the program implementation will be carried out.

In RIA the information aspect is of great importance. The experience study shows that at present the effective tools for collecting information have been developed (Tikhomirov, Kashanin \& Tretyakov, 2010). So, the most common tools are:

- public consultations. Either representatives of a number of companies are invited, or information about the impending bill is published, and the concerned parties are invited to make comments. Typically used at early stages of preparation of a bill;

- "engineering approach" ("method of a typical plant"), which involves calculations for one typical enterprise of the studied sphere of influence, or for several;

- surveys of representatives of the concerned groups, population, territorial business communities;

- econometric methods for collecting information;

- general equilibrium models on the scale of macroeconomics;

- review of the bureaucratic expenses and costs of the state to ensure the implementation of legislation (Broder \& Morrall, 1997).

Ultimately, summing-up of the analysis should be completed by the assessment of the achievement degree of the set goals of the state regulatory impact. Below is a logic diagram of the achievement analysis of the objectives of the innovation project, the innovative program, a policy that allows building a system of monitoring and the assessment consistency.

Table 2. The logical principle of analysis and assessment of achieving the regulatory impact objectives

\begin{tabular}{|c|c|c|c|c|}
\hline $\begin{array}{l}\text { Levels of the } \\
\text { objectives } \\
\text { (The project logic) }\end{array}$ & $\begin{array}{l}\text { Measurable indicators of } \\
\text { the achievement }\end{array}$ & $\begin{array}{l}\text { Sources and methods } \\
\text { confirm the achievements }\end{array}$ & to & Assumptions and risks \\
\hline Common goals & $\begin{array}{l}\text { Indicators of achieving the } \\
\text { common goals }\end{array}$ & $\begin{array}{l}\text { Sources and methods } \\
\text { confirm the achievement }\end{array}$ & to & ------ \\
\hline $\begin{array}{l}\text { The objectives of } \\
\text { the project }\end{array}$ & $\begin{array}{l}\text { Indicators of achieving the } \\
\text { specific objectives }\end{array}$ & $\begin{array}{l}\text { Sources and methods } \\
\text { confirm the achievement }\end{array}$ & to & $\begin{array}{l}\text { Assumptions that affect the relationship between } \\
\text { specific and general objectives, risks of failure to } \\
\text { achieve }\end{array}$ \\
\hline The results & Indicators of achievement & $\begin{array}{l}\text { Sources and methods } \\
\text { confirm the achievement }\end{array}$ & to & $\begin{array}{l}\text { Assumptions that affect the relationship between the } \\
\text { results and the specific objectives, risks of failure to } \\
\text { achieve }\end{array}$ \\
\hline Actions & $\begin{array}{l}\text { Required human and } \\
\text { physical resources }\end{array}$ & $\begin{array}{l}\text { The cost of human } \\
\text { physical resources }\end{array}$ & and & $\begin{array}{l}\text { Assumptions that affect the relationship between the } \\
\text { actions and the results, the risks of not achieving }\end{array}$ \\
\hline
\end{tabular}


It should be noted that no matter how advanced and complex the considered systems for assessing the regulatory impacts were, they do not form management decisions, they only serve as a tool for their adoption, but it is quite a strong tool, because the quality and content of management decisions depends on what is the quality, reliability of the conducted analysis and the validity of the conclusion, which is formed on the analysis results.

The considered system of the management decisions analysis should contribute to a better understanding of the possible consequences of regulation, including from the point of view of benefits and costs of the regulatory impacts, but must also take into account the interests of all economic entities, provide public "feedback", increase personal responsibility of the heads of the executive authorities for the results of the reforms.

\section{Discussion}

The works of Belyaev, Derman \& Tsygankov (2011), Tikhomirov \& Kashanin (2010), Kozlovskaya \& Elmurzayeva (2012), Caulley (1993), Broder \& Morrall (1997) and others are devoted to a review of methodological approaches to assessing the regulatory impact of the state on the economy.

Problems of regulatory impact assessment of the state in the sphere of innovation development of market services are considered in the works of Kiselev (2013), Gilyazutdinova (2008), Egorov (2010), Stiglitz (1997), Fayzrakhmanov (2013) and others.

However, a number of issues relating to the criteria of the formation of methodological approaches to assessing the regulatory impact of the state in the sphere of innovation development of the market services, the indicators to assess and improve its effectiveness remain poorly understood.

\section{Conclusion}

In conclusion, it should be noted, that there are currently no holistic, scientifically-developed methodology and a set of methods and tools of project management in relation to innovative projects and programs in the service industries. There are only more or less general approaches to solving such problems, and the set of tools and methods in each case is selected or developed separately. The study on the possibilities of application of the project management methodology in the implementation of large programs is extremely important. Currently in our country there is a certain amount of regulatory documents in the field of project management. However, it is not a full legal framework for project management at the state level. It is necessary to create a common standard in the field of project management, to develop special provisions for typical strategic public projects, which would describe the algorithms of their passage through expert authorities and decision-makers.

\section{Recommendations}

The obtained results allow justifying, classifying and structuring the main methodological approaches to assessing the regulatory impact of the state in the sphere of the innovation development of market services. In addition, the results can be useful to the state administration bodies in the process of improving the regulatory impact of the state on individual industries and the economy as a whole.

\section{References}

Belyaev, A. N., Derman, D. O., \& Tsygankov, D. B. (2011). Methodological approaches to meta-evaluation of the quality of the conclusions on the regulatory impact assessment. Design, monitoring and evaluation, 1 , 45-54.

Broder, I., \& Morrall, J. (1997). Collecting and using data for regulatory decision-making. OECD.

Caulley, D. (1993). Overview of approaches to program evaluation: the five generations. In Guthrie J. (Ed.), The Australian Public Sector: Pathways to Change in the 1990s (pp. 124-133). IIR Publications: Sydney.

Egorov, E. V. (2010). Innovation development of services. Moscow. The Economics faculty of Moscow State University named after M.V. Lomonosov.

Gilyazutdinova, I. V. (2008). Method of assessing the level of innovation development of the production potential of enterprises in the regional economic system. Bulletin of Chuvash University, 3, 331-342.

Gilyazutdinova, I. V., Kiselev, S. V., \& Faizrakhmanov, M. D. (2013). The Interaction of government and business organizations as a condition of innovation development of the industrial infrastructure in the service sector. Bulletin of Kazan Technological University, 4, 340-346.

Kozlovskaya, O. V., \& Elmurzayeva, R. A. (2012). The introduction and development of the Institute of regulatory impact assessment in the formation and implementation of public policy. Bulletin of Tomsk State University, 363, 165-166. 
Stiglitz, J. (1997). Economics of the public sector. Moscow. INFRA-M.

Tikhomirov, A. V., \& Kashanin, S. A. (2010). Legal documents: impact assessment. Jurisprudence. Moscow.

Tsygankov, D. B. (2010). Evaluation of programs and policies: methodology and application. Moscow: State University-higher school of Economics.

\section{Copyrights}

Copyright for this article is retained by the author(s), with first publication rights granted to the journal.

This is an open-access article distributed under the terms and conditions of the Creative Commons Attribution license (http://creativecommons.org/licenses/by/3.0/). 